\title{
The SPI-1-like Type III secretion system: more roles than you think
}

\author{
Frank Egan', Matthieu Barret ${ }^{2,3,4}$ and Fergal O'Gara ${ }^{1,5}$ * \\ ${ }^{1}$ BIOMERIT Research Centre, School of Microbiology, University College Cork, Cork, Ireland \\ 2 UMR1345 Institut de Recherche en Horticulture et Semences, Institut National de la Recherche Agronomique, Beaucouzé, France \\ ${ }^{3}$ UMR1345 Institut de Recherches en Horticulture et Semences, Agrocampus Ouest, Beaucouzé, France \\ ${ }^{4}$ Université d'Angers, UMR1345 Institut de Recherches en Horticulture et Semences, SFR4207 QUASAV, Beaucouzé, France \\ ${ }^{5}$ School of Biomedical Sciences, Curtin University, Perth, WA, Australia
}

\section{Edited by:}

Carmen R. Beuzón, University of

Málaga, Spain

Reviewed by:

Franz Narberhaus, Ruhr University

Bochum, Germany

Adam Schikora, Justus-Liebig

University of Giessen, Germany

\section{*Correspondence:}

Fergal O'Gara, BIOMERIT Research

Centre, School of Microbiology,

University College Cork, Cork, Ireland

e-mail:f.ogara@ucc.ie
The type III secretion system (T3SS) is a protein delivery system which is involved in a wide spectrum of interactions, from mutualism to pathogenesis, between Gram negative bacteria and various eukaryotes, including plants, fungi, protozoa and mammals. Various phylogenetic families of the T3SS have been described, including the Salmonella Pathogenicity Island 1 family (SPI-1). The SPI-1 T3SS was initially associated with the virulence of enteric pathogens, but is actually found in a diverse array of bacterial species, where it can play roles in processes as different as symbiotic interactions with insects and colonization of plants. We review the multiple roles of the SPI-1 T3SS and discuss both how these discoveries are changing our perception of the SPI-1 family and what impacts this has on our understanding of the specialization of the T3SS in general.

Keywords: SPI-1, T3SS, phytopathogens, plant, Salmonella, insect, amoeba

\section{INTRODUCTION}

Non-flagellar Type III secretion systems (NF-T3SSs) are macromolecular complexes, apparently derived from exaptation of the flagella for the delivery of bacterial effectors into eukaryotic cells (Abby and Rocha, 2012). These macromolecular complexes can be divided schematically into three parts: (i) a transmembrane export apparatus, (ii) an extracellular needle or pilus and (iii) a translocon which forms a pore in the host cell membrane (Cornelis, 2006). Additional elements, such as chaperones which can facilitate the association between effectors and the T3SS injectisome, and an ATPase which catalyzes the dissociation of the effector chaperone complex prior to secretion are also important for proper T3SS functioning (Akeda and Galan, 2005).

Multiple phylogenetic analyses based on proteins involved in the assembly of the transmembrane export apparatus have split the NF-T3SSs into seven distinct families: SPI-1 (also known as the Inv-Mxi-Spa family), SPI-2, Hrp1, Hrp2, Ysc, Rhizobiales, and Chlamydiales (Pallen et al., 2005; Troisfontaines and Cornelis, 2005; Barret et al., 2013b). From initial characterization and genomic distribution, the Ysc, Chlamydiales, SPI-1, and SPI-2 families were associated with animal-bacterial interactions while the Rhizobiales, Hrp1, and Hrp2 families were associated with plant-bacterial interactions. As well as host-range, phylogenetic groups differed in their extracellular appendages, with plant-associated families having long flexible pili, while animal pathogens have short rigid needles, which in some cases (e.g., SPI-2) can be appended by a filamentous sheath (Chakravortty et al., 2005) The core components are highly conserved between each family, which probably contributes to the phenomenon of promiscuous secretion; that is, there are multiple reports of effector secretion via non-cognate T3SS families, including effectors which are normally used during the infection of animals being heterologously expressed and secreted via phytopathogenic T3SSs and vice versa (Anderson et al., 1999; Subtil et al., 2001).

\section{HISTORY AND PHYLOGENETIC ANALYSIS OF SPI-1 T3SSS}

The Salmonella pathogenicity island 1 (SPI-1) is a genetic locus which is involved in invasion of non-phagocytic cells by Salmonella spp. (Galan and Curtiss, 1989). Molecular analyses have revealed that the vast majority of the genes located in this region encoded a T3SS (Galan, 1996). Consequently the term SPI-1 was coined for this T3SS. Homologs of SPI-1 T3SS have been identified and found to be essential virulence determinants in other mammalian pathogens such as Chromobacterium, Escherichia, Shigella, and Yersinia species (Barinaga, 1996; Miki et al., 2010), thus confirming its role in animal/human pathogenesis. However, recent reports in the literature have highlighted the presence of SPI-1 T3SSs outside of mammalian pathogenic bacteria, such as Sodalis (Dale et al., 2005), Erwinia (Triplett et al., 2006), Xanthomonas (Alavi et al., 2008; Marguerettaz et al., 2011), Pantoea (Correa et al., 2012), and Pseudomonas species (Barret et al., 2013a; Redondo-Nieto et al., 2013). Concurrently, the rise in genome sequences is revealing that the SPI-1 T3SS is found in a multitude of other bacterial strains (Figure 1).

Phylogenetic analyses have consistently split the SPI-1 family into 2 sub-clusters (Marguerettaz et al., 2011; Abby and Rocha, 2012; Barret et al., 2013b). One sub-cluster has a greater frequency of classical enteric bacteria such as Salmonella, Shigella, and Escherichia coli, while the other contains other bacterial strains associated with plant insect or soil environments. However, both environmental strains and mammalian pathogens can be found in each sub-cluster so it is difficult to see 


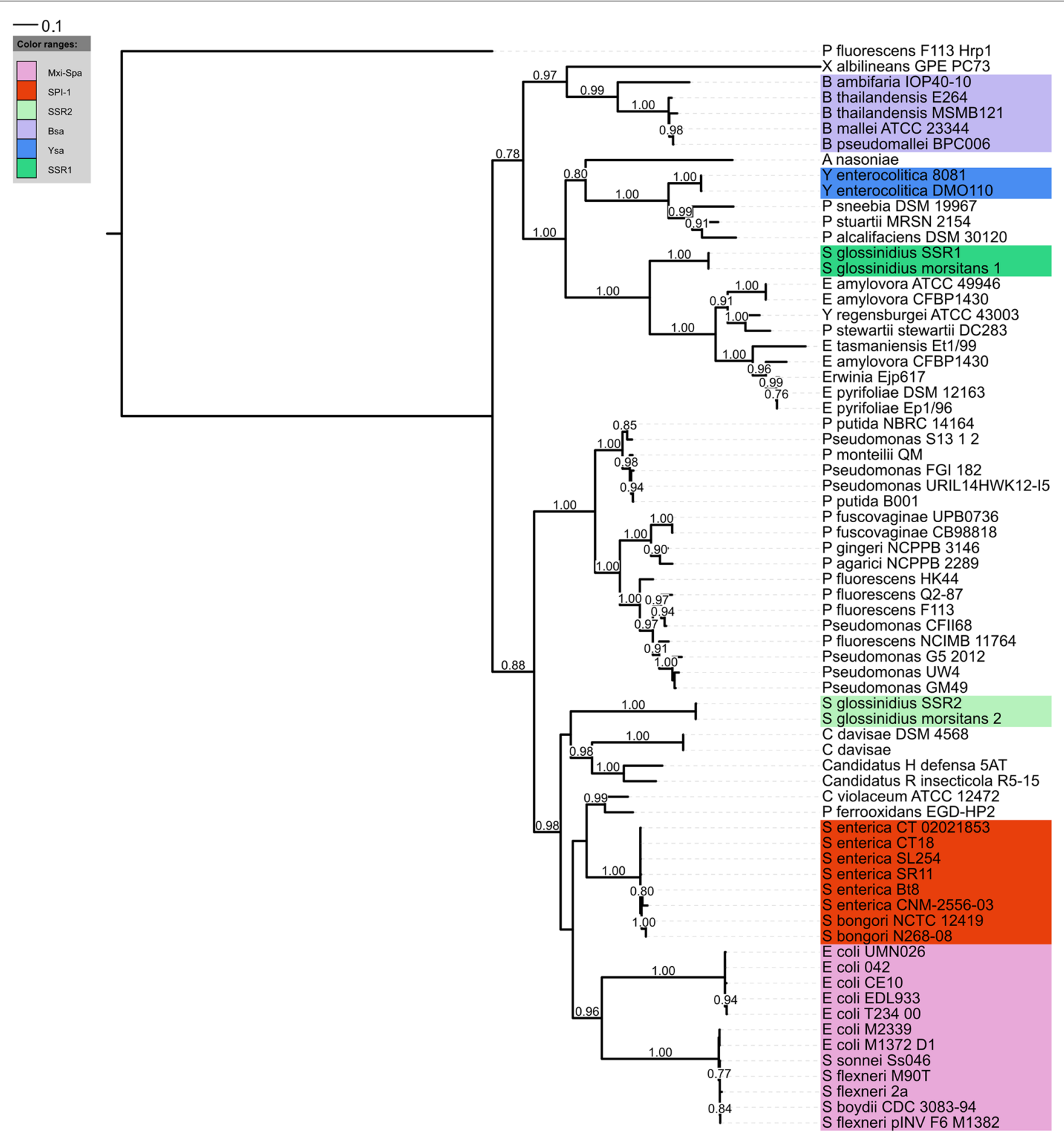

FIGURE 1 | Phylogenetic distribution of the SPI-1 T3SS. A distance tree (maximum likelihood based on the WAG model) was calculated from InvA homologs (COG4789) of the SPI-1 family. RscV (COG4789) from the Hrp1 T3SS of $P$. fluorescens F113 was used as an outgroup. Only aLRT support values greater than 0.75 (1000 replicates) are displayed.

that this phylogenetic split has any meaningful implication for host range. Of course there may be other interesting features related with phylogeny, for instance through evolution some differences in T3SS apparatus or secretion mechanism might arise which could be particular to certain phylogenetic branches. One possible example might be that Pseudomonas strains possessing the SPI-1 T3SS do not have a strong homolog to the invJ gene which controls needle length, suggesting the needle length or regulation thereof is different in these strains.

\section{MULTIPLE ROLES OF SPI-1 T3SSS}

As mentioned, the SPI-1 T3SS is best known for its role in mammalian pathogenesis, but it is being recognized as being important in a many different settings (Figure 2). The high occurrence of SPI-1 T3SS in genome sequences of insect symbionts such 


\section{Insects: invasion/persistence}

- Sodalis glossinidius (Dale et al., 2005)

- Pantoea stewartii (Correa et al., 2012)
Mammals: cell invasion

- Salmonella (Galan, 1996)

- Chromobacterium violaceum (Miki et al., 2010)

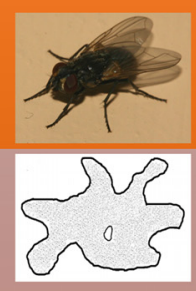

Amoeba: killing or avoidance

- Salmonella (Bleasdale et al., 2009)

- Pseudomonas fluorescens (Barret et al., 2013)
Plants: immune modulation

- Salmonella (Schikora et al., 2011; Shirron and Yaron, 2011)

FIGURE 2 | Multiple roles of the SPI-1 T3SS. The SPI-1 T3SS was first implicated in virulence towards mammals, but has since been shown to mediate interactions with other animals, protozoa, and plants.

as Arsenophonus nasoniae, "Candidatus Hamiltonella defensa", "Candidatus Regiella insecticola," and Sodalis glossinidius could indicate that SPI-1 is often necessary for persistence in insect hosts, expanding the known host range of the SPI-1-type T3SS and demonstrating a non-pathogenic function for this T3SS family. Indeed, two SPI-1 family T3SS are found in S. glossinidius, one which is required for cell invasion and another "needleless" T3SS which is required for replication of this bacterium in insect cells (Dale et al., 2005). Interestingly, a recent study has also highlighted that the SPI-1 T3SS of Pantoea stewartii is required for persistence of this bacterium in the flea beetle, an important vector for this maize pathogen (Correa et al., 2012). Moreover, protein-coding genes involved in the assembly of the SPI-1 NFT3SS are also abundant in arthropoda-associated microbiomes (Barret et al., 2013b).

Other SPI-1 T3SSs are involved in interactions with free-living protozoa. SPI-1 T3SS gene expression of Salmonella and Pseudomonas fluorescens is induced during contact with amoebae (Bleasdale et al., 2009; Barret et al., 2013a). In Salmonella a modest effect was seen on amoeba survival after hilA, a key regulator of the SPI-1 system, was mutated, but as non-T3SS genes are also regulated by HilA the contribution of the SPI-1 T3SS to this phenotype is not clear (Tezcan-Merdol et al., 2004). The presence of the SPI-1 system did not enable the plant-growth promoting rhizobacterium
P. fluorescens F113 to survive in or kill amoeba, but instead helped the bacteria avoid amoeboid grazing. As the amoeba still consume $P$. fluorescens F113 in the absence of alternatives, it is not clear whether this is the main function of the SPI-1 system, or a useful additional function.

Finally, SPI-1 T3SS is also important during bacterial-plant interactions. For instance SPI-1 and SPI-2 T3SS deficient strains of Salmonella spp. are compromised for survival in planta while the SPI-1 mutant had reduced ability to repress the hypersensitive response of Arabidopsis (Schikora et al., 2011). In addition, the SPI-1 T3SS of Salmonella is also involved in suppression of the early plant immune response of Nicotiana tabacum (Shirron and Yaron, 2011). In contrast, the SPI-1 T3SS of Salmonella enterica elicits Medicago defense, which limits bacterial colonization of plant tissue (Iniguez et al., 2005). Plant defense responses are often categorized as either PTI or ETI, based on whether they are triggered by pathogen-associated molecular pathogens or effectors, respectively. While the structural apparatus of the T3SS might elicit the Medicago PTI, mutants lacking the translocator SipB reached higher numbers in planta, suggesting the plant's response might be at least partially due to the presence of translocated effectors. Indeed, one effector of the SPI-2 T3SS, SseF, has been shown to trigger the hypersensitive response in N. benthamiana when expressed transiently or translocated by the T3SS of 
phytopathogen Xanthomonas campestris, though the presence of S. enterica did not elicit this response (Üstün et al., 2012). While there are other examples of multi-host pathogens that infect both plants and animals, this is the only reported instance of a bacterium using the same secretion system in both processes, though E. coli does use its extended T3SS filament for plant attachment, and encodes several homologs to phytopathogenic effectors (Tobe et al., 2006; Shaw et al., 2008).

The SPI-1 system might also play a role in cell aggregation similar to, but independent from, biofilm formation. Indeed, when overexpressed on a vector, the SPI-1 locus induced clumping of $S$. enterica Typhimurium in media, seemingly due to an extracellular sheath composed at least partly of SPI-1 proteins (Jennings et al., 2012). Somewhat analogously the Hrp T3SS is involved in pellicle formation in Erwinia chrysanthemi (Yap et al., 2005). In light of the lack of evidence for SPI-1-mediated effector translocation into plant cytosol it remains a possibility that SPI-1 induced formation of cell aggregates in planta could shield the bacteria from plant defense receptors, though visual evidence from Salmonella inoculation of Arabidopsis has not shown large clumps of cells (Schikora et al., 2008). It is harder to envisage how cell aggregation could explain the SPI-1 dependent induction of the Medicago plant defense in response to infection with S. typhimurium, but in these set of experiments only a translocator was mutated, so it is possible the phenotype seen was due to perception of this translocator instead of perception of translocated effectors within the plant cytosol.

\section{THE T3SS TRANSLOCATION PROCESS IN PLANTS AND ANIMALS}

While T3SS function was initially understood within the confines of the model system(s) that are still predominantly used to characterize it, there has been a growing recognition that bacteria can utilize the same T3SS to mediate interactions with several different hosts (Preston, 2007). A role for the same T3SS with both plant and animal hosts is the ultimate demonstration of the flexibility of the T3SS, as this challenges the classical separation of NF-T3SSs from animal and plant-associated bacteria, which mainly differ in their translocators and extracellular appendages. This is presumably because of the greater challenge of delivering effectors across the additional barrier of the cell wall, which can be reinforced through callose deposition at sites of infection (Luna et al., 2011). Instead of the short $(\sim 60 \mathrm{~nm})$, apparently ancestral, needle, the Hrp-T3SS has a long $(\sim 1-2 \mu \mathrm{m})$ flexible pilus presumed to be an adaptation to the thickness of the plant cell wall (Cornelis, 2006). The phytopathogenic translocator repertoire is more complex and variable than that of animal pathogens, which simply have three essential translocators. Though proteins involved in translocation which show homology to one particular animal translocator, SipB, can be found in some phytopathogens, this is not universal (Meyer et al., 2006). Instead, small, heat stable proteins known as harpins, which are exclusive to and possibly ubiquitous in, bacteria possessing the Hrp T3SS, have been implicated in the translocation process (Kvitko et al., 2007; Choi et al., 2013).

In light of the plant-related activities of the SPI-1 system it seems that having a long flexible pilus and harpins to facilitate delivery of type 3 effectors (T3Es) into plants is not a strict requirement, but given the strong association between the Hrp
T3SS family and phytopathogens it seems likely that these factors are advantageous. How Salmonella could deliver effectors into the plant cell cytosol remains to be determined, though formation of elongated needles through dysregulation of needle length control has been observed in vitro following mutation (Kubori et al., 2000). It is important to note, however, that translocation of effectors into plant cells by Salmonella remains to be demonstrated.

It is interesting to note that $P$. fluorescens MFM1032 use a T3SS which probably belongs to the Hrp family to lyse macrophages and interfere with the growth of amoeba (Sperandio et al., 2012). Unfortunately, in the absence of a genome sequence it is not clear whether this strain possesses the plant-associated pilus and translocator repertoire.

\section{SPI-1 TYPE 3 EFFECTORS}

Each bacterial species delivers its own unique set of T3Es into host cells and it is necessary to define their role(s) to fully understand any T3SS-dependent phenotype.

Unfortunately, from the SPI-1 family only effectors from classical mammalian pathogens have been characterized to date. As these effectors have been extensively reviewed elsewhere (McGhie et al., 2009; Parsot, 2009), the examples in the next section are not intended to be exhaustive, but instead serve to emphasize the commonalities of T3Es generally by comparing effectors secreted by the SPI- 1 and Hrp families.

Although extremely diverse, described T3Es are composed of less than 40 motifs or domains which can often interfere with conserved eukaryotic cellular processes such as the mitogen activated protein kinase (MAPK) signaling pathway (Dean, 2011). Indeed, several effectors which bacteria use during infection of plants or animals have been characterized after heterologous expression in non-host yeast (Siggers and Lesser, 2008; Tripathi et al., 2010; Salomon et al., 2011). Therefore, it is possible that Salmonella uses a subset of the same effectors to affect both plants and animals by interfering with the same processes in both.

Many described SPI-1 effectors can be categorized as being involved in host cell invasion or host immune response modulation, and many T3Es secreted by Hrp T3SSs are also dedicated to downplaying the host immune response (Grant et al., 2006). This is especially pertinent as SPI-1 dependent phenotypes in plant models all result ultimately from differential plant immune response. SPI-1 T3Es SptP and AvrA act to inhibit the action of the MAPK-dependent immune response pathway while Hrp effector HopAO1 possibly acts downstream of the MAPK activation to suppresses plant defenses (Murli et al., 2001; Lin et al., 2003; Underwood et al., 2007; Jones et al., 2008). Hrp effector AvrptoB and SPI-1 effector SopA are ubiquitin ligases which also modulate the host immune response (Abramovitch et al., 2006; Zhang et al., 2006). SopE activates caspase-dependent immune responses in macrophages (Hoffmann et al., 2010), while caspase-like proteases also control programmed cell death in plants (Hoffmann et al., 2010; Woltering, 2010). The SptP T3E has an additional function as dephosphorylase of the mammalian ATPase valosincontaining protein (Humphreys et al., 2009), and could potentially have the same activity with the plant homolog AAA+ ATPase (Shi et al., 1995). 
Other conserved targets of both plant and animal SPI-1 systems are suggested by similar localization patterns, e.g., Hrp effectors HopG1 and HopAA1-1 and SPI-1 effectors SipB and SopA are reported to be able to localize to the mitochondria (Hernandez et al., 2003; Layton et al., 2005; Munkvold et al., 2008; Block et al., 2010). Understanding these underlying commonalities we can begin to appreciate how multi-host T3SS-dependent interactions evolve as well as form hypotheses about which effectors are utilized by Salmonella in interactions with plants. Alternatively, it is possible that the Salmonella SPI-1 T3SS might translocate an entirely different, yet uncharacterized, set of proteins into plant cells.

Only recently have SPI-1 T3Es from outside mammalian pathogens been identified, and their mode of action remains to be determined. Using a conserved chaperone-binding domain (CCBD) sequence, recognized by class IB chaperones, two SPI1 T3Es of S. glossinidius (SG0576 and SG0764) were predicted, and then confirmed to be secreted in a T3SS-dependent manner (Costa et al., 2012). This CCBD sequence could be employed to detect others SPI-1 T3Es in genome sequences possessing class IB chaperones, such as P. fluorescens HK44 and Pseudomonas sp. GM49 (Barret et al., 2013a). Bioinformatic prediction has also been used to identify effectors. Two putative protein coding-genes (PSF113_1802 and PSF113_4041) were predicted to be potential effectors of Pseudomonas strains, since they possess T3 secretion signal, are only encoded in Pseudomonas genome sequences encoding the T3SS SPI-1 cluster. Though their translocation remains to be confirmed, their expression is induced by the SPI-1 T3SS transcriptional activator HilA in P. fluorescens F113 (Barret et al., 2013a). As well as using CCBD sequences to detect other SPI-1 T3Es in genome sequences, improving in silico prediction models, which are mainly based on the amino acid frequencies and biochemical properties of the effector's $\mathrm{N}$-terminal region, may result in more T3Es being found, allowing us to develop our understanding of the SPI-1 T3SS in its many diverse roles (Wang et al., 2011; Wang et al., 2013).

\section{CONCLUSION}

Phylogenetic analyses have highlighted seven different families of T3SS and have been useful for unraveling the evolutionary history of the system, as well as for highlighting the relationship between T3SS family and (a) the specificities of its translocation process as well as (b) broader categories of target organisms. The SPI-1 system is associated with and best understood in the context of mammalian pathogenesis, but as our knowledge advances it becomes clear that this is a system with multiple functions in different hosts, perhaps especially with insects as it is particularly abundant among insect related bacteria. In light of the division between T3SS families that were found to target plant or animals in early T3SS research, it was tempting to speculate that certain T3SS families were limited to plants or non-plants but evidence is mounting that this is not the case. This raises questions about our assumptions about the specialization of the plantrelated translocation process. This, and the growing appreciation of the functional relatedness of the diverse set of T3E, suggests that the various bacterial-eukaryote interactions mediated by the T3SS follow similar templates.
Though the original categorical divisions between phytopathogenic and animal pathogenic processes are being eroded, this paradigm is still useful as long as we remember that in biology, exceptions are the rule. What adaptions are needed for the SPI-1 system to interact with plant cells is an intriguing question, and when the Hrp systems are so strongly associated with plants, the prospect that no adaptions are needed is maybe more intriguing still.

\section{ACKNOWLEDGMENTS}

This research was supported in part by grants awarded by the Science Foundation of Ireland (SSPC2 12/RC/2275, 13-TIDA-B2625, 07/IN.1/B948，12/TIDA/B2411，12/TIDA/B2405，09/RFP/BMT 2350); the Department of Agriculture, Fisheries, and Food (DAFF11/F/009 MabS, FIRM/RSF/CoFoRD; FIRM 08/RDC/629); the Environmental Protection Agency (EPA 2008-PhD/S-2), the Irish Research Council for Science, Engineering, and Technology (PD/2011/2414; RS/2010/2413), the European Commission (FP7-PEOPLE-2013-ITN, 607786; OCEAN2012, 287589; FP7KBBE-2012-6, CP-TP 311975; FP7-KBBE-2012-6, CP-TP-312184; Marie Curie 256596); and the Marine Institute (Beaufort award C2CRA 2007/082); Teagasc (Walsh Fellowship 2013), and the Health Research Board (HRA/2009/146).

\section{REFERENCES}

Abby, S. S., and Rocha, E. P. (2012). The non-flagellar type III secretion system evolved from the bacterial flagellum and diversified into host-cell adapted systems. PLoS Genet. 8:e1002983. doi: 10.1371/journal.pgen.1002983

Abramovitch, R. B., Janjusevic, R., Stebbins, C. E., and Martin, G. B. (2006). Type III effector AvrPtoB requires intrinsic E3 ubiquitin ligase activity to suppress plant cell death and immunity. Proc. Natl. Acad. Sci. U.S.A 103, 2851-2856. doi: 10.1073/pnas.0507892103

Akeda, Y., and Galan, J. E. (2005). Chaperone release and unfolding of substrates in type III secretion. Nature 437, 911-915. doi: 10.1038/nature03992

Alavi, S. M., Sanjari, S., Durand, F., Brin, C., Manceau, C., and Poussier, S. (2008). Assessment of the genetic diversity of Xanthomonas axonopodis pv. phaseoli and Xanthomonas fuscans subsp. fuscans as a basis to identify putative pathogenicity genes and a type III secretion system of the SPI-1 family by multiple suppression subtractive hybridizations. Appl. Environ. Microbiol. 74, 3295-3301. doi: 10.1128/AEM.02507-07

Anderson, D. M., Fouts, D. E., Collmer, A., and Schneewind, O. (1999). Reciprocal secretion of proteins by the bacterial type III machines of plant and animal pathogens suggests universal recognition of mRNA targeting signals. Proc. Natl. Acad. Sci. U.S.A. 96, 12839-12843. doi: 10.1073/pnas.96.22.12839

Barinaga, M. (1996). A shared strategy for virulence. Science 272, 1261-1263. doi: 10.1126/science.272.5266.1261

Barret, M., Egan, F., Moynihan, J., Morrissey, J. P., Lesouhaitier, O., and O'Gara, F. (2013a). Characterization of the SPI-1 and Rsp type three secretion systems in Pseudomonas fluorescens F113. Environ. Microbiol. Rep. 5, 377-386. doi: $10.1111 / 1758-2229.12039$

Barret, M., Egan, F., and O'Gara, F. (2013b). Distribution and diversity of bacterial secretion systems across metagenomic datasets. Environ. Microbiol. Rep. 5, 117126. doi: 10.1111/j.1758-2229.2012.00394.x

Bleasdale, B., Lott, P. J., Jagannathan, A., Stevens, M. P., Birtles, R. J., and Wigley, P. (2009). The Salmonella pathogenicity island 2-encoded type III secretion system is essential for the survival of Salmonella enterica serovar typhimurium in free-living amoebae. Appl. Environ. Microbiol. 75, 1793-1795. doi: 10.1128/AEM.02033-08

Block, A., Guo, M., Li, G., Elowsky, C., Clemente, T. E., and Alfano, J. R. (2010). The Pseudomonas syringae type III effector HopG1 targets mitochondria, alters plant development and suppresses plant innate immunity. Cell. Microbiol. 12, 318-330. doi: 10.1111/j.1462-5822.2009.01396.x

Chakravortty, D., Rohde, M., Jager, L., Deiwick, J., and Hensel, M. (2005). Formation of a novel surface structure encoded by Salmonella pathogenicity Island 2. EMBO J. 24, 2043-2052. doi: 10.1038/sj.emboj.7600676 
Choi, M. S., Kim, W., Lee, C., and Oh, C. S. (2013). Harpins, multifunctional proteins secreted by Gram-negative plant-pathogenic bacteria. Mol. Plant. Microbe Interact. 26, 1115-1122. doi: 10.1094/MPMI-02-13-0050-CR

Cornelis, G. R. (2006). The type III secretion injectisome. Nat. Rev. Microbiol. 4 , 811-825. doi: 10.1038/nrmicro1526

Correa, V. R., Majerczak, D. R., Ammar El, D., Merighi, M., Pratt, R. C., Hogenhout, S. A., et al. (2012). The bacterium Pantoea stewartii uses two different type III secretion systems to colonize its plant host and insect vector. Appl. Environ. Microbiol. 78, 6327-6336. doi: 10.1128/AEM.00892-12

Costa, S. C., Schmitz, A. M., Jahufar, F. F., Boyd, J. D., Cho, M. Y., Glicksman, M A., et al. (2012). A new means to identify type 3 secreted effectors: functionally interchangeable class IB chaperones recognize a conserved sequence. MBio 3:e0243-11. doi: 10.1128/mBio.00243-11

Dale, C., Jones, T., and Pontes, M. (2005). Degenerative evolution and functional diversification of type-III secretion systems in the insect endosymbiont Sodalis glossinidius. Mol. Biol. Evol. 22, 758-766. doi: 10.1093/molbev/msi061

Dean, P. (2011). Functional domains and motifs of bacterial type III effector proteins and their roles in infection. FEMS Microbiol. Rev. 35, 1100-1125. doi 10.1111/j.1574-6976.2011.00271.x

Galan, J. E. (1996). Molecular genetic bases of Salmonella entry into host cells. Mol. Microbiol. 20, 263-271. doi: 10.1111/j.1365-2958.1996.tb02615.x

Galan, J. E., and Curtiss, R., 3rd. (1989). Cloning and molecular characterization of genes whose products allow Salmonella typhimurium to penetrate tissue culture cells. Proc. Natl. Acad. Sci. U.S.A. 86, 6383-6387. doi: 10.1073/pnas.86. 16.6383

Grant, S. R., Fisher, E. J., Chang, J. H., Mole, B. M., and Dangl, J. L. (2006). Subterfuge and manipulation: type III effector proteins of phytopathogenic bacteria. Annu. Rev. Microbiol. 60, 425-449. doi: 10.1146/annurev.micro.60.080805.142251

Hernandez, L. D., Pypaert, M., Flavell, R. A., and Galan, J. E. (2003). A Salmonella protein causes macrophage cell death by inducing autophagy. J. Cell. Biol. 163, 1123-1131. doi: 10.1083/jcb.200309161

Hoffmann, C., Galle, M., Dilling, S., Kappeli, R., Muller, A. J., Songhet, P., et al. (2010). In macrophages, caspase-1 activation by SopE and the type III secretion system-1 of S. typhimurium can proceed in the absence of flagellin. PLoS ONE 5:e12477. doi: 10.1371/journal.pone.0012477

Humphreys, D., Hume, P. J., and Koronakis, V. (2009). The Salmonella effector SptP dephosphorylates host AAA + ATPase VCP to promote developmen of its intracellular replicative niche. Cell Host Microbe 5, 225-233. doi: 10.1016/j.chom.2009.01.010

Iniguez, A. L., Dong, Y., Carter, H. D., Ahmer, B. M., Stone, J. M., and Triplett, E. W. (2005). Regulation of enteric endophytic bacterial colonization by plant defenses. Mol. Plant Microbe Interact. 18, 169-178. doi: 10.1094/MPMI-18-0169

Jennings, M. E., Quick, L. N., Ubol, N., Shrom, S., Dollahon, N., and Wilson, J. W. (2012). Characterization of Salmonella type III secretion hyperactivity which results in biofilm-like cell aggregation. PLoS ONE 7:e33080. doi: 10.1371/journal.pone. 0033080

Jones, R. M., Wu, H., Wentworth, C., Luo, L., Collier-Hyams, L., and Neish, A. S. (2008). Salmonella AvrA coordinates suppression of host immune and apoptotic defenses via JNK pathway blockade. Cell Host Microbe 3, 233-244. doi: 10.1016/j.chom.2008.02.016

Kubori, T., Sukhan, A., Aizawa, S. I., and Galan, J. E. (2000). Molecular characterization and assembly of the needle complex of the Salmonella typhimurium type III protein secretion system. Proc. Natl. Acad. Sci. U.S.A. 97, 10225-10230. doi: 10.1073/pnas.170128997

Kvitko, B. H., Ramos, A. R., Morello, J. E., Oh, H. S., and Collmer, A. (2007). Identification of harpins in Pseudomonas syringae pv. tomato DC3000, which are functionally similar to HrpK1 in promoting translocation of type III secretion system effectors. J. Bacteriol. 189, 8059-8072. doi: 10.1128/JB.01146-07

Layton, A. N., Brown, P. J., and Galyov, E. E. (2005). The Salmonella translocated effector SopA is targeted to the mitochondria of infected cells. J. Bacteriol. 187, 3565-3571. doi: 10.1128/JB.187.10.3565-3571.2005

Lin, S. L., Le, T. X., and Cowen, D. S. (2003). SptP, a Salmonella typhimurium type III-secreted protein, inhibits the mitogen-activated protein kinase pathway by inhibiting Raf activation. Cell Microbiol. 5, 267-275. doi: 10.1046/j.14625822.2003.t01-1-00274.x

Luna, E., Pastor, V., Robert, J., Flors, V., Mauch-Mani, B., and Ton, J. (2011). Callose deposition: a multifaceted plant defense response. Mol. Plant Microbe Interact. 24, 183-193. doi: 10.1094/MPMI-07-10-0149
Marguerettaz, M., Pieretti, I., Gayral, P., Puig, J., Brin, C., Cociancich, S., et al. (2011). Genomic and evolutionary features of the SPI-1 type III secretion system that is present in Xanthomonas albilineans but is not essential for xylem colonization and symptom development of sugarcane leaf scald. Mol. Plant Microbe Interact. 24, 246-259. doi: 10.1094/MPMI-08-10-0188

McGhie, E. J., Brawn, L. C., Hume, P. J., Humphreys, D., and Koronakis, V. (2009). Salmonella takes control: effector-driven manipulation of the host. Curr. Opin. Microbiol. 12, 117-124. doi: 10.1016/j.mib.2008.12.001

Meyer, D., Cunnac, S., Gueneron, M., Declercq, C., Van Gijsegem, F., Lauber, E., et al. (2006). PopF1 and PopF2, two proteins secreted by the type III protein secretion system of Ralstonia solanacearum, are translocators belonging to the HrpF/NopX family. J. Bacteriol. 188, 4903-4917. doi: 10.1128/JB.00180-06

Miki, T., Iguchi, M., Akiba, K., Hosono, M., Sobue, T., Danbara, H., et al. (2010). Chromobacterium pathogenicity island 1 type III secretion system is a major virulence determinant for Chromobacterium violaceum-induced cell death in hepatocytes. Mol. Microbiol. 77, 855-872. doi: 10.1111/j.1365-2958.2010.07248

Munkvold, K. R., Martin, M. E., Bronstein, P. A., and Collmer, A. (2008). A survey of the Pseudomonas syringae pv. tomato DC3000 type III secretion system effector repertoire reveals several effectors that are deleterious when expressed in Saccharomyces cerevisiae. Mol. Plant Microbe Interact. 21, 490-502. doi: 10.1094/MPMI-21-4-0490

Murli, S., Watson, R. O., and Galan, J. E. (2001). Role of tyrosine kinases and the tyrosine phosphatase SptP in the interaction of Salmonella with host cells. Cell Microbiol. 3, 795-810. doi: 10.1046/j.1462-5822.2001.00158.x

Pallen, M. J., Beatson, S. A., and Bailey, C. M. (2005). Bioinformatics, genomics and evolution of non-flagellar type-III secretion systems: a Darwinian perspective. FEMS Microbiol. Rev. 29, 201-229. doi: 10.1016/j.femsre.2005.01.001

Parsot, C. (2009). Shigella type III secretion effectors: how, where, when, for what purposes? Curr. Opin. Microbiol. 12, 110-116. doi: 10.1016/j.mib.2008.12.002

Preston, G. M. (2007). Metropolitan microbes: type III secretion in multihost symbionts. Cell Host Microbe 2, 291-294. doi: 10.1016/j.chom.2007.10.004

Redondo-Nieto, M., Barret, M., Morrissey, J., Germaine, K., Martinez-Granero, F., Barahona, E., et al. (2013). Genome sequence reveals that Pseudomonas fluorescens F113 possesses a large and diverse array of systems for rhizosphere function and host interaction. BMC Genomics 14:54. doi: 10.1186/1471-2164-14-54

Salomon, D., Dar, D., Sreeramulu, S., and Sessa, G. (2011). Expression of Xanthomonas campestris pv. vesicatoria type III effectors in yeast affects cell growth and viability. Mol. Plant Microbe Interact. 24, 305-314. doi: 10.1094/MPMI-0910-0196

Schikora, A., Carreri, A., Charpentier, E., and Hirt, H. (2008). The dark side of the salad: Salmonella typhimurium overcomes the innate immune response of Arabidopsis thaliana and shows an endopathogenic lifestyle. PLoS ONE 3:e2279. doi: 10.1371/journal.pone.0002279

Schikora, A., Virlogeux-Payant, I., Bueso, E., Garcia, A. V., Nilau, T., Charrier, A., et al. (2011). Conservation of Salmonella infection mechanisms in plants and animals. PLoS ONE 6:e24112. doi: 10.1371/journal.pone.0024112

Shaw, R. K., Berger, C. N., Feys, B., Knutton, S., Pallen, M. J., and Frankel, G. (2008). Enterohemorrhagic Escherichia coli exploits EspA filaments for attachment to salad leaves. Appl. Environ. Microbiol. 74, 2908-2914. doi: 10.1128/AEM. 02704-07

Shi, J., Dixon, R. A., Gonzales, R. A., Kjellbom, P., and Bhattacharyya, M. K. (1995). Identification of cDNA clones encoding valosin-containing protein and other plant plasma membrane-associated proteins by a general immunoscreening strategy. Proc. Natl. Acad. Sci. U.S.A. 92, 4457-4461. doi: 10.1073/pnas.92. 10.4457

Shirron, N., and Yaron, S. (2011). Active suppression of early immune response in tobacco by the human pathogen Salmonella typhimurium. PLoS ONE 6:e18855. doi: 10.1371/journal.pone.0018855

Siggers, K. A., and Lesser, C. F. (2008). The yeast Saccharomyces cerevisiae: a versatile model system for the identification and characterization of bacterial virulence proteins. Cell Host Microbe 4, 8-15. doi: 10.1016/j.chom.2008.06.004

Sperandio, D., Decoin, V., Latour, X., Mijouin, L., Hillion, M., Feuilloley, M. G., et al. (2012). Virulence of the Pseudomonas fluorescens clinical strain MFN1032 towards Dictyostelium discoideum and macrophages in relation with type III secretion system. BMC Microbiol. 12:223. doi: 10.1186/1471-2180-12-223

Subtil, A., Parsot, C., and Dautry-Varsat, A. (2001). Secretion of predicted Inc proteins of Chlamydia pneumoniae by a heterologous type III machinery. Mol. Microbiol. 39, 792-800. doi: 10.1046/j.1365-2958.2001.02272.x 
Tezcan-Merdol, D., Ljungstrom, M., Winiecka-Krusnell, J., Linder, E., Engstrand, L., and Rhen, M. (2004). Uptake and replication of Salmonella enterica in Acanthamoeba rhysodes. Appl. Environ. Microbiol. 70, 3706-3714. doi: 10.1128/AEM.70.6.3706-3714.2004

Tobe, T., Beatson, S. A., Taniguchi, H., Abe, H., Bailey, C. M., Fivian, A., et al. (2006). An extensive repertoire of type III secretion effectors in Escherichia coli $\mathrm{O} 157$ and the role of lambdoid phages in their dissemination. Proc. Natl. Acad. Sci. U.S.A 103, 14941-14946. doi: 10.1073/pnas.0604891103

Tripathi, R., Singh Naorem, S., Dureja, C., Haldar, S., Mondal, A. K., and Raychaudhuri, S. (2010). VopF, a type III effector protein from a non-O1, non-O139 Vibrio cholerae strain, demonstrates toxicity in a Saccharomyces cerevisiae model. J. Med. Microbiol. 59, 17-24. doi: 10.1099/jmm.0.012336-0

Triplett, L. R., Zhao, Y., and Sundin, G. W. (2006). Genetic differences between blight-causing Erwinia species with differing host specificities, identified by suppression subtractive hybridization. Appl. Environ. Microbiol. 72, 7359-7364. doi: 10.1128/AEM.01159-06

Troisfontaines, P., and Cornelis, G. R. (2005). Type III secretion: more systems than you think. Physiology 20, 326-339. doi: 10.1152/physiol.00011.2005

Underwood, W., Zhang, S., and He, S. Y. (2007). The Pseudomonas syringae type III effector tyrosine phosphatase HopAO1 suppresses innate immunity in Arabidopsis thaliana. Plant J. 52, 658-672. doi: 10.1111/j.1365-313X.2007.03262.x

Üstün, ş., Müller, P., Palmisano, R., Hensel, M., and Börnke, F. (2012). SseF, a type III effector protein from the mammalian pathogen Salmonella enterica, requires resistance-gene-mediated signalling to activate cell death in the model plant Nicotiana benthamiana. New Phytol. 194, 1046-1060. doi: 10.1111/j.1469-8137.2012.04124.x

Wang, Y., Sun, M., Bao, H., Zhang, Q., and Guo, D. (2013). Effective identification of bacterial type III secretion signals using joint element features. PLoS ONE 8:e59754. doi: 10.1371/journal.pone.0059754
Wang, Y., Zhang, Q., Sun, M. A., and Guo, D. (2011). High-accuracy prediction of bacterial type III secreted effectors based on position-specific amino acid composition profiles. Bioinformatics 27, 777-784. doi: 10.1093/bioinformatics/btr021

Woltering, E. J. (2010). Death proteases: alive and kicking. Trends Plant Sci. 15, 185-188. doi: 10.1016/j.tplants.2010.02.001

Yap, M. N., Yang, C. H., Barak, J. D., Jahn, C. E., and Charkowski, A. O. (2005). The Erwinia chrysanthemi type III secretion system is required for multicellular behavior. J. Bacteriol. 187, 639-648. doi: 10.1128/JB.187.2.639648.2005

Zhang, Y., Higashide, W. M., McCormick, B. A., Chen, J., and Zhou, D. (2006). The inflammation-associated Salmonella sopA is a HECT-like E3 ubiquitin ligase. Mol. Microbiol. 62, 786-793. doi: 10.1111/j.1365-2958.2006.05407.x

Conflict of Interest Statement: The authors declare that the research was conducted in the absence of any commercial or financial relationships that could be construed as a potential conflict of interest.

Received: 17 December 2013; accepted: 25 January 2014; published online: 12 February 2014.

Citation: Egan F, Barret M and O'Gara F (2014) The SPI-1-like Type III secretion system: more roles than you think. Front. Plant Sci. 5:34. doi: 10.3389/fpls.2014.00034 This article was submitted to Plant-Microbe Interaction, a section of the journal Frontiers in Plant Science.

Copyright $\odot 2014$ Egan, Barret and O'Gara. This is an open-access article distributed under the terms of the Creative Commons Attribution License (CC BY). The use, distribution or reproduction in other forums is permitted, provided the original author(s) or licensor are credited and that the original publication in this journal is cited, in accordance with accepted academic practice. No use, distribution or reproduction is permitted which does not comply with these terms. 